me that when the cow came from the pasture the night previously he noticed she was dull and "all of a shake," and that she only gave a very small quantity of milk although she had given her full quantity in the morning. As it had been a nasty wet day, he thought she had taken a chill, and gave her a drink composed of ginger, coriander, and aniseed, with warm beer.

"The symptoms I observed were as follows: Pulse 50 , temp. $100^{\circ} \mathrm{F}$., horns and ears very cold, muzzle cold and dry, drooping of the eyelids, and lopping of the ears. When made to move she did so with difficulty, staggered about, and seemed half stupefied. The near hind quarter of the udder was slightly enlarged and inflamed, and the milk contained in all the quarters resembled curds and whey. There was also marked purging. I administered a stimulating draught, had her well clothed, and ordered her three quarts of oatmeal gruel three times a day.

"The cow gradually recovered, and by the 5 th day all the symptoms had disappeared, save that the secretion of milk remained arrested."

\title{
TWO CASES OF BRAIN DISEASE IN THE HORSE.
}

\author{
By T. \& W. Fletcher, M.R.C.V.S., Sheffield.
}

As a small contribution to the pathology of brain affections, we send for publication the following notes regarding two cases that recently occurred in our practice.

CASE I.-The subject in this instance was a milk-cart horse, about r6 or 17 years of age. The animal had always appeared to be of a particularly nervous temperament, but it was only about six months before his death that he began to show decided symptoms of brain disease. The most noticeable of these symptoms was the abnormal position in which he carried his head, which he kept inclined with the nose towards the left side and the poll towards the right, almost like a horse with a diseased ear which he dreaded to have touched. When the head was pushed sharply away from the near side he appeared about to fall, and indeed did sometimes topple over. He had formerly been used to plough, but latterly he was unable to control his movements sufficiently well to walk in the furrow. He had always been a good backer; and even after the onset of the above-mentioned symptoms he could back, when made to do so with care, but he seemed to have partially lost control over his limbs and to go dizzy. He was always able to lie down and get up without any assistance, urine and freces were passed normally, and the appetite remained good until the last. He was in good condition, and able to walk three miles to the horse-slaughterer's yard to be killed, on the 5 th of April last.

The post-mortem examination showed that the brain was normal save for the presence of an irregular-shaped grey body, about half the volume of a walnut, and situated between the cerebellum and medulla oblongata on the left side. This body, which was partially blended with the so-called choroid plexus of the fourth ventricle, had a soft and somewhat greasy consistence; and when a particle of it was examined microscopically, it appeared to be almost entirely composed 
of the characteristic tabular crystals of cholesterin. The cerebellum and medulla were slightly depressed for the reception of the mass.

CASE II.-This case occurred in our practice some time ago, and it is mentioned here on account of the symptoms having been similar, although the brain lesion had a different situation. The animal was a six-years-old cart horse which had to be destroyed after exhibiting symptoms of loss of power and want of co-ordination. These symptoms were more pronounced than in the previous case, and ultimately the horse was unable to rise. After death the cause of these symptoms was found to be an inward bulging of the cranial vault, brought about by the development of a serous abscess in the temporal fossa.

\section{PARALYSIS IN HORSES FED ON PEA STRAW.}

By Thomas Campbell, M.R.C.V.S., Kirby-Moorside, Yorkshire.

ON the 4th of March last I was called to a farm in this district, to see some horses that appeared to be partially paralysed. On my arrival I found that one of the animals-a bay pregnant mare-showed distinct indications of loss of power in the hind quarters, and several others were affected in the same way but to a less degree. The inability in each case was manifested by a most noticeable side-to-side swaying motion when the animal walked. The temperature and respirations were found to be normal, but the pulse was rather slow34 per minute in the mare. The appetite, I was informed, was good.

My thoughts were naturally directed towards the food and water; inquiry appeared to show that the water could not be incriminated, but I ascertained that the character of the food was at least open to suspicion. The horses had for some time been fed exclusively on unthrashed pea straw cut into chaff, and inspection showed that this was of inferior quality and contained a considerable quantity of sand, or loam.

Coming to the conclusion that the food was at fault, I ordered an entire change, stopping the pea chaff and substituting oats and hay, with oatmeal gruel to drink. At the same time I administered a mild aperient to the mare.

On the following day (5th March) I found the pregnant mare down, unable to regain her feet, and tympanitic. The temperature was normal, and the pulse and respirations were a little acceleratedapparently as the result of struggling. The bladder was full, and had to be emptied by means of the catheter. The condition of the other animals remained unaltered.

6th March.-Mare still unable to rise, appetite good, catheter had again to be used. I found that one of the horses appeared to have lost the contractile power of the rectum, and ordered enemata, a little belladonna being added to each. I also prescribed nux vomica and sulphate of iron, to be given twice daily with the food.

$7_{\text {th }}$ March.-Condition of animals unaltered. Bay mare put in slings.

8th March--On this date a black mare and a black gelding were found to be down and unable to rise. 